\title{
A Biblioteca Digital de Teses e Dissertações da Universidade de São Paulo
}

\author{
Paulo Cesar Masiero \\ Presidente da Comissão Central de Informática (CCI) e Diretor do \\ Instituto de Ciências Matemáticas e da Computação de São Carlos \\ -ICMC/USP. masiero@icmc.sc.usp.br
}

\section{Carlos Frederico Bremer}

Professor da Área de Engenharia de Produção da Escola de Engenharia de São Carlos - EESC/USP. bremer@sc.usp.br

\section{Teresinha das Graças Coletta}

Bibliotecária, diretora técnica do Sistema Integrado de Bibliotecas da USP - SIBi/USP. coletta@sibi.usp.br

\section{Maria de Lourdes Rebucci Lirani \\ lurdinha@sc.usp.br}

\section{Rogério Toshiaki Kondo}

rogerio@sc.usp.br

\section{Antonio C. Aragão}

Analistas de Sistemas do Centro de Informática de São Carlos CISC/USP. ac.aragao@bol.com.br

\section{Elaine Paiva Mosconi}

Bibliotecária, mestranda em Engenharia de Produção da Escola de Engenharia de São Carlos - EESC/USP, pesquisadora do NUMA Núcleo de Manufatura Avançada. elainepm@sc.usp.br

\section{Aziz Donizzetti Cavalheiro Salem}

Analista de Sistemas do Sistema Integrado de Bibliotecas da USP SIBi/USP. aziz@sibi.usp.br

\section{Resumo}

Apresentação dos aspectos principais da Biblioteca Digital de Teses e Dissertações da Universidade de São Paulo (USP): o processo de desenvolvimento adotado para a implementação do site, a tecnologia utilizada, a arquitetura e a funcionalidade. Discussão sobre a Biblioteca Digital no processo de pós-graduação da USP. Relato das várias decisões não-técnicas adotadas ao longo do projeto, que tiveram grande impacto no resultado final.

Palavras-chave

Biblioteca digital; Teses on-line.

\section{The University of São Paulo Digital Library of Theses and Dissertations}

\begin{abstract}
The main aspects involved in the development of the digital library of theses and dissertations of the University of São Paulo (USP) are discussed: the process adopted to accomplish the objective, the technology used, and the digital library architecture and functionality. Two other aspects are also discussed: how the digital library is inserted in the whole USP graduation process and various non technical, crucial decisions taken throughout the development process.

Keywords
\end{abstract}

Digital libraries; Online theses.

\section{INTRODUÇÃO}

A Universidade de São Paulo (USP) implantou em junho de 2001 a sua Biblioteca Digital de Teses e Dissertações ${ }^{1}$, com o objetivo de facilitar o acesso remoto a essa parte de sua produção intelectual. A USP possui o maior sistema de pós-graduação do país e produz anualmente cerca de 1.500 teses de doutorado e 2.600 dissertações de mestrado, em 259 programas de pós-graduação. A diversidade e a complexidade desse sistema, aliadas à novidade do tema, já que não há até o momento outra iniciativa institucional desse porte no país, apresentaram vários desafios à equipe encarregada do seu desenvolvimento.

A Biblioteca Digital engloba teses e dissertações nas áreas de humanas, exatas e biológicas, com diferentes estruturas e conteúdos. Das mais simples (apenas texto) até aquelas mais complexas (compostas de vídeos e imagens). Nesse contexto, é verdadeira a afirmação de Fox \& Marchionini²: "Bibliotecas digitais envolvem a integração de sistemas complexos, incluindo coleção de documentos com estruturas, mídias e conteúdos variados, além de uma mistura de componentes de hardware e software interoperando, ao longo de diferentes estruturas de dados, algoritmos de processamento e múltiplas pessoas, comunidades e instituições com diferentes objetivos, políticas e culturas". Iniciativa semelhante à da USP é apresentada por Urs e Raghavan $^{3}$, sobre a biblioteca digital de teses da Índia.

O objetivo deste artigo é relatar e discutir as principais decisões e o processo organizacional utilizado, visando a facilitar a sua reprodução em outras universidades do país. Descreve-se o processo de desenvolvimento, a tecnologia utilizada e a arquitetura da Biblioteca Digital. Sucintamente, são apresentadas as suas principais funcionalidades e sua interface com os usuários. Mostrase como a Biblioteca Digital está inserida no processo de pós-graduação da USP e apresenta-se uma discussão sobre vários problemas não-técnicos que se mostraram cruciais para o sucesso da iniciativa.

\section{O PROCESSO DE DESENVOLVIMENTO}

O processo foi iniciado pelo reitor da Universidade. Foi constituída a Comissão de Implementação da Biblioteca Digital de Teses e Dissertações na USP, através de Portaria ${ }^{4}$, formada pelo presidente da CCI (Comissão Central de Informática 
A Biblioteca Digital de Teses e Dissertações da Universidade de São Paulo

da USP), pelo diretor técnico do SIBi (Sistema Integrado de Bibliotecas da USP), por um docente e por um analista de sistemas. Uma equipe fixa de dois analistas de sistemas apoiou a Comissão. Outros analistas de sistemas e bibliotecários colaboraram em tempo parcial, auxiliando em tarefas específicas. $O$ projeto teve a duração de um ano, e, dentre os membros, apenas um analista de sistemas trabalhou em tempo integral. O pró-reitor de pós-graduação atuou como usuário e facilitador do projeto e como intermediário entre a Comissão e o Conselho de Pós-graduação, que representava os usuários (internos) da Biblioteca Digital. Ao longo do projeto, foram feitas três reuniões com o Conselho de Pós-Graduação para tomada de decisões quanto à forma de sensibilização dos docentes e alunos de pós-graduação. Além disso, foi fundamental a participação da Consultoria Jurídica para a definição quanto à legislação, em especial, a questão dos direitos autorais.

A Comissão estabeleceu um plano de trabalho que compreendeu sete grandes fases, ilustradas na figura 1. Inicialmente procedeu-se a uma prospecção tecnológica com o objetivo de definir padrões a serem utilizados e a estratégia de desenvolvimento. Foram pesquisados softwares e metodologias de várias empresas e visitados vários sites de universidades do exterior para definir as funcionalidades gerais de uma biblioteca digital. Feito isso, a Comissão de Implementação decidiu pela utilização do formato PDF para os arquivos e as plataformas de software/ hardware e o software aplicativo da Networked Digital Library of Theses and Dissertations (NDLDT), uma iniciativa internacional de apoio ao desenvolvimento de bibliotecas digitais ${ }^{5}$. Para isso, a USP associou-se a essa organização e teve acesso ao código fonte de módulos de software já desenvolvidos. Esse software não contém um robô de busca e, portanto, outros estudos foram feitos para definir esse componente.

Em seguida deu-se início ao processo de engenharia de software. O software da NDLTD foi instalado e adaptado. Nesse processo, muitos componentes, inicialmente programados em PEARL, foram refeitos em PHP, e novos componentes foram desenvolvidos pela equipe. Para os usuários, foi definida uma nova interface, desenvolvido um cadastro e traduzida parte do material de auxílio. Foi programada também a interface com o Sistema de PósGraduação (FÊNIX), destinado aos controles de matrículas nos cursos de pós-graduaação da USP, e o Banco de Dados Bibliográficos (DEDALUS), que abriga a Base
Tese, com os registros bibliográficos e resumos das teses defendidas, em formato MARC. Foi adotada uma abordagem de prototipação, em que se produziu rapidamente uma versão operacional (em quatro meses) e a partir daí foram produzidas mais três versões.

Enquanto se desenvolvia o software, parte da Comissão encarregou-se de estudar as macroatividades relacionadas genericamente a um programa de pós-graduação para definir em quais pontos a criação de uma biblioteca digital iria interferir nas rotinas. Era necessário definir precisamente como essa intervenção se daria, bem como para, a partir desse processo, definir outras tarefas não técnicas que a Comissão teria de executar para implantar o sistema. Esse estudo produziu um modelo do processo de pós-graduação da USP e uma lista de tarefas que foram distribuídas entre os membros da equipe e executadas de acordo com o processo descrito na figura 1. Como exemplo, citam-se: a) definição de diretrizes para a elaboração de teses e dissertações, baseadas nos manuais já existentes na Universidade, sob responsabilidade do SIBi; b) definição do conjunto de metadados para a descrição bibliográfica das teses e dissertações, segundo os padrões do Dublin Core; c) aquisição e instalação, em todas as bibliotecas, de cópias do sistema Adobe Acrobat (a cargo do Centro de Computação de cada campus e do SIBi).

Com a operacionalização da primeira versão da Biblioteca Digital, deu-se início ao projeto piloto, com a participação de dez programas de pós-graduação, com peculiaridades distintas, para que se pudesse avaliar os principais pontos de dificuldades para as diferentes áreas do conhecimento. Para isso, preparou-se um treinamento para os funcionários das bibliotecas, das seções de pós-graduação e dos centros de informática envolvidos. Assim, os programas já treinados passaram a inserir teses no sistema, testando os procedimentos definidos. O treinamento foi avaliado e depois prosseguiu estendendo-se para todos os demais programas de pós-graduação. Para o lançamento do sistema, a Comissão preparou um plano de divulgação que incluiu a confecção de cartazes, banners, kits (composto de pasta, mouse pad, adesivos e folder) e divulgação pelas mídias 
Paulo Cesar Masiero / Carlos Frederico Bremer / Teresinha das Graças Coletta / Maria de Lourdes Rebucci Lirani /

Rogério Toshiaki Kondo / Antonio C. Aragão / Elaine Paiva Mosconi / Aziz Donizzetti Cavalheiro Salem

internas da USP (Jornal da USP, outdoors, e-mails, site do SIBi e Portal da USP), com o objetivo de atingir os estudantes de pós-graduação, os orientadores e toda a comunidade acadêmica.

Visando à operação e evolução do sistema, foram definidas as responsabilidades dos centros de informática, das bibliotecas e dos programas de pós-graduação após a implantação.

Aliado às discussões da criação da Biblioteca Digital, foi idealizado o Portal do Conhecimento da USP (http://www.saber.usp.br) ${ }^{6}$, a ser constituído de diversas bibliotecas digitais, sendo a de teses e dissertações o seu primeiro produto. Com isso, todas as futuras bibliotecas digitais na Universidade devem observar os conceitos do Portal, para o qual está em fase de definição um comitê gestor.

\section{TECNOLOGIA E ARQUITETURA DA BIBLIOTECA DIGITAL}

A Biblioteca Digital foi desenvolvida em plataforma de hardware com processador Intel, sistema operacional Linux, distribuição Red Hat, Apache com SSL (openssl e mod_ssl) como servidor Web e MySQL para armazenamento de dados. O sistema foi dividido em dois sites: um de trabalho, para uso dos alunos, bibliotecários, seções de pós-graduação e administradores e outro público, para acesso às teses pela Internet. Os dois sites estão, no momento, instalados no mesmo servidor, que também hospeda os serviços de banco de dados e de Web. O servidor Apache foi configurado para atender a dois IPs.

Uma configuração atende às necessidades do site de trabalho, utilizando os scripts em PERL e acesso ao banco de dados para inserção, remoção e atualização e SSL para o processamento de contas e senhas pela Internet. Outra configuração atende às necessidades da Biblioteca Digital usando páginas escritas em PHP e acesso ao banco de dados para consulta. Nesse site, usa-se SSL para cadastramento dos visitantes.
Planeja-se substituir o hardware por uma estação de trabalho RISC de grande porte. Embora a configuração atual mantenha os dois sites em um mesmo computador, pode-se separá-los, se for conveniente. O site de trabalho pode ser duplicado para atender a um particular campus, mantendo apenas um banco de dados local. Nesse caso poderia ser mantido um site global na sede da Biblioteca Digital, que armazenaria as teses de cada campus. Ossp evitaria tráfego desnecessário na Wan da Universidade.

Como já mencionado, a NDLDT não disponibiliza um robô de busca. Vários robôs foram testados pela equipe e optou-se pelo software Insearch, da INSITE [7], que cede, em convênio, o direito de uso gratuito pela USP. Esse componente pode ser facilmente mudado para outros robôs de busca comerciais ou de uso livre.

A figura 2 mostra uma visão geral da Biblioteca Digital. A submissão é feita pelos alunos no site de trabalho. Cada aluno recebe uma senha com validade temporária, que expira quando a tese ou dissertação é inserida no site. Nesse site, os alunos encontram instruções para submeter as teses e são guiados pelo sistema durante o processo de submissão. 
Os dados das teses são replicados dos sistemas institucionais (DEDALUS e FENIX) para o site de trabalho. Quando o aluno submete a tese à Biblioteca Digital, o sistema busca no FÊNIX os metadados referentes à banca examinadora, data da defesa, orientador e o título. $\mathrm{O}$ aluno complementa informações tais como o resumo e o abstract. Quando a versão impressa e a versão digital estão disponíveis, a biblioteca da Unidade completa os dados bibliográficos: número de tombo e classificação (código de localização). A Biblioteca Digital gera então um registro bibliográfico no padrão MARC, que é automaticamente inserido no DEDALUS.

Os funcionários das seções de pós-graduação geram senhas para os alunos, inserem e conferem dados e verificam se a tese submetida corresponde àquela defendida. Os bibliotecários inserem e conferem os dados bibliográficos, conferem os arquivos submetidos e liberam a tese para consulta em http://www.teses.usp.br, se não houver restrições do autor. O sistema gera automaticamente mensagens para os autores e orientadores sobre os eventos ocorridos, como, por exemplo, que a tese foi submetida ou que foi liberada para consulta. O sistema está sendo preparado também para enviar mensagens sobre estatísticas de consulta aos orientadores.

O módulo público tem o objetivo principal de permitir a consulta às teses disponíveis. O sistema indexa tanto os dados da tese, ou metadados (título, autor, banca examinadora etc.), como o conteúdo da tese. A busca pode ser feita pela Unidade USP, pelo programa de pósgraduação, pela área de concentração, pelo nome do autor e por qualquer palavra encontrada no texto. Está em fase de implantação a busca por outros atributos, tais como orientador e data da defesa. Esse módulo apresenta também as estatísticas de uso do sistema, de forma bastante ampla e variada. Uma visão geral da Biblioteca Digital é apresentada na figura 3 .

Ci. Inf., Brasília, v. 30, n. 3, p. 34-41, set./dez. 2001

\section{FUNCIONALIDADE DA BIBLIOTECA DIGITAL}

O acesso à Biblioteca Digital pode ser feito também pelo site institucional da USP [8], que remete para a página do Portal do Conhecimento. Esse Portal agrega a Biblioteca Digital de Teses e Dissertações e, futuramente, outras bibliotecas digitais que venham a ser desenvolvidas. O design da interface com o usuário segue o design geral da página principal da USP.

A página principal da Biblioteca Digital apresenta notícias gerais sobre a USP, datas previstas de defesas de teses, alimentadas descentralizadamente pelos próprios programas de pós-graduação, e as últimas teses inseridas. Há também o acesso ao módulo de cadastramento dos usuários. Estes têm a opção de receber informações sobre novas teses inseridas em áreas de sua escolha. A ligação para estatística mostra grande variedade de dados: as teses mais visitadas em geral, por Unidade e área de concentração, estatísticas de acesso ao site por países, por páginas, por hits etc.

A busca a partir da página principal remete a uma listagem das teses encontradas (se for por Unidade ou programa, por exemplo). Clicando-se em uma das teses aparecem os metadados da tese e o acesso ao texto completo. Isto pode ser feito também a partir do DEDALUS, através de links. A figura 3 mostra a página inicial da Biblioteca Digital, a página de entrada e uma página com dados de uma tese. 
Paulo Cesar Masiero / Carlos Frederico Bremer / Teresinha das Graças Coletta / Maria de Lourdes Rebucci Lirani / Rogério Toshiaki Kondo / Antonio C. Aragão / Elaine Paiva Mosconi / Aziz Donizzetti Cavalheiro Salem

PROCESSO NO QUAL A BIBLIOTECA DIGITAL ESTÁ INSERIDA

As atividades envolvidas no processo de pós-graduação, tanto dos alunos e orientadores, como da secretaria de pós-graduação e das bibliotecas foram analisadas e registradas formalmente. As atividades foram classificadas como:

- atividades independentes da Biblioteca Digital;

- atividades modificadas pela criação da Biblioteca Digital;

- atividades novas introduzidas a partir da criação da Biblioteca Digital.

A tabela 1 apresenta uma visão parcial desses macroprocessos. No documento original, há ainda alguns outros subníveis, e colunas para registrar os recursos usados em cada atividade, e as informações de entrada e de saída de cada processo.

Pode-se verificar na tabela que as atividades novas estão destacadas em negrito, e as atividades que já existiam, modificadas com a introdução da biblioteca digital, aparecem em itálico. A maior parte das atividades novas concentra-se na conclusão do processo. Porém, a Comissão de Implementação incluiu uma atividade de divulgação da Biblioteca Digital logo no início das atividades de pós-graduação, para que o aluno se familiarize com o assunto.

Nota-se também que a parte principal do processo está centrada no aluno/autor, que é o responsável pela redação da tese e geração do original digital, sua conversão para o formato PDF, preenchimento, assinatura e entrega do documento de autorização de cópia e submissão à Biblioteca Digital. As bibliotecas têm o trabalho novo de conferir a versão digital, mas o trabalho de processamento da versão impressa é facilitado. À seção de pós-graduação é acrescido o trabalho de gerar senhas para os alunos e a conferência de alguns dados da versão digital. No futuro esse trabalho pode ser modificado, pois a versão impressa pode ser abolida, como já ocorre em algumas universidades no exterior.

\section{DIFICULDADES NÃO-TÉCNICAS}

Vários problemas não-técnicos surgiram durante o desenvolvimento da Biblioteca Digital. Muitos tinham potencial para paralisar ou inviabilizar o desenvolvimento do projeto se não solucionado a contento, pois envolviam a parte mais importante: o fornecedor de conteúdo, isto é, os alunos de pós-graduação e seus orientadores. Esses problemas são de natureza geral e têm grande probabilidade de ocorrer em outras implementações.

Em seguida, são comentados os principais problemas ocorridos na implementação, na ótica da Comissão e as soluções adotadas.

O primeiro ponto importante é a questão do direito autoral. Ampla discussão ocorreu entre a Comissão, o Conselho de Pós-graduação e a Consultoria Jurídica da USP. Ficou definido que o autor da tese é o aluno e que, como autor, só ele pode autorizar a disposição on-line da sua dissertação e/ou tese na Biblioteca Digital. Para tanto, foi elaborado um documento que deve ser analisado e preenchido pelo aluno antes de inserir seu trabalho.

Debateu-se também se os usuários do sistema deveriam pagar para consultar ou fazer cópia das teses. Essa questão é controvertida, pois concorrem para a execução de uma tese ou dissertação o autor (o aluno), a Universidade e, muitas vezes, órgãos públicos de apoio à pesquisa, principalmente Fundação Coordenação de Aperfeiçoamento de Pessoal de Nível Superior (Capes), Fundação de Amparo à Pesquisa do Estado de São Paulo (Fapesp) e Conselho Nacional de Desenvolvimento Científico e Tecnológico (CNPq). Além disso, a Universidade tem um custo para manter o sistema em operação. Prevaleceu a noção de que, por se tratar de uma universidade pública, o acesso deveria ser livre, mas com os usuários cadastrados para o usar o sistema. Tornou-se claro também que, ao decidir-se por qualquer cobrança no futuro, os autores deverão receber um percentual do arrecadado, a título de direito autoral. Alguns serviços adicionais que poderão ser implementados, como a entrega de versões impressas e encadernadas das teses a partir de pedidos dos usuários, deverão ser cobrados para ressarcimento dos custos.

Durante o desenvolvimento do projeto, nos treinamentos e nas visitas às unidades, em contato com alunos e orientadores, dúvidas foram levantadas quanto à efetividade da iniciativa, e a Comissão notou que em muitas áreas havia receio em tornar disponível o trabalho científico para um público potencialmente tão grande como o propiciado pela Internet. Alguns dos receios foram claramente identificados:

- maior facilidade para que as teses sejam copiadas, aumentando os casos de plágio; 
TABELA 1

Macroprocessos das atividades de pós-graduação na USP

\begin{tabular}{lll}
\hline Níveis & Atividade & Responsável \\
\hline
\end{tabular}

$1 \quad$ REGISTRAR MATRÍCULA DE PÓS-GRADUANDOS

1.1 Preencher formulário de admissão

1.2 Cadastrar dados do pós-graduando

1.3 Arquivar formulário preenchido e assinado

1.4 Divulgar a Biblioteca Digital de Teses e Dissertações

2 CURSAR DISCIPLINAS

2.1 Selecionar disciplinas

2.2 Inscrever-se em disciplinas

2.3 Assistir a aulas

2.4 Cumprir requisitos da disciplina

2.5 Integralizar o número de créditos do programa

3 QUALIFICAR

3.1 Preparar texto para qualificação

3.2 Fazer qualificação

$3.3 \quad$ Obter aprovação

4 ESCREVER TESE/DISSERTAÇÃO

4.1 Estudar Diretrizes para elaboração de dissertações e teses

4.2 Redigir texto da tese ou dissertação

4.2.1 Padronizar texto segundo as Diretrizes

5 DEFENDER TÍTULO

5.1 Finalizar texto de acordo com os resultados da qualificação

5.2 Marcar data de Defesa

5.3 Depositar versão impressa na secretaria pós-graduação

5.3.1 Entregar 4 cópias impressas (Dissertação)

5.3.2 Entregar 6 cópias impressas (Tese)

5.3.3 Assinar formulário de entrega

5.4 Enviar texto à banca

5.5 Cadastrar dados da defesa no FÊNIX

5.5.1 Cadastrar título segundo ABNT

5.5.2 Cadastrar demais dados

5.7 Fazer a defesa

5.8 Realizar correções

6 FINALIZAR PÓS-GRADUAÇÃO

6.1 Entregar versão final impressa

6.2 Aprender funcionamento da biblioteca digital

6.2.1 Consultar help on-line

6.2.2 Consultar manual impresso

6.3. Preparar a submissão da versão digital

6.3.1 Preencher formulário de autorização de divulgação e

cópia da tese ou dissertação

6.3.2 Imprimir formulário de autorização

6.3.3 Entregar formulário preenchido e assinado na SPG

6.3.4 Solicitar e Receber senha da SPG

6.3.5 Converter tese/dissertação para formato especificado

6.3.6 Usar ID e senha para entrar no site de serviço

6.3.7 Preencher formulário de submissão da tese ou dissertação

6.4 Submeter teses ou dissertação eletronicamente (Upload)

6.4.1 Fazer upload da versão digital

6.4.2 Encaminhar aviso de submissão para orientador e

SPG por e-mail

Pós-graduando

Sec. Pós-grad;

Sec. Pós-grad;

Sec. Pós-grad. e Bib.

Pós-graduando

Pós-graduando

Pós-graduando

Pós-graduando

Pós-graduando

Pós-graduando

Pós-graduando

Pós-graduando

Pós-graduando

Pós-graduando

Pós-graduando

Pós-graduando

Pós-graduando

Pós-graduando

Pós-graduando

Pós-graduando

Pós-graduando

Sec. Pós-grad.

Sec. Pós-grad.

Sec. Pós-grad.

Sec. Pós-grad.

Pós-graduando

Pós-graduando

Pós-graduando

Pós-graduando

Pós-graduando

Pós-graduando

Pós-graduando

Pós-graduando

Pós-graduando

Pós-graduando

Pós-graduando

Pós-graduando

Pós-graduando

Pós-graduando

Pós-graduando

Sistema TDE

Sistema TDE 
Paulo Cesar Masiero / Carlos Frederico Bremer / Teresinha das Graças Coletta / Maria de Lourdes Rebucci Lirani /

Rogério Toshiaki Kondo / Antonio C. Aragão / Elaine Paiva Mosconi / Aziz Donizzetti Cavalheiro Salem (continuação)

\begin{tabular}{|c|c|c|}
\hline Níveis & Atividade & Responsável \\
\hline 6.5 & Gerenciar Versões Digitais & \\
\hline 6.5.1 & Verificar periodicamente teses submetidas & Sec. Pós-grad. \\
\hline 6.5 .2 & Revisar dados da tese/dissertação submetida & Sec. Pós-grad. \\
\hline 6.5.3 & Checar formato do arquivo PDF & Sec. Pós-grad. \\
\hline 6.5.3.1 & Abrir páginas aleatórias da teses ou dissertação & Sec. Pós-grad. \\
\hline 6.5.3.2 & Verificar aparência de figuras, tabelas etc. & Sec. Pós-grad. \\
\hline 6.5.3.3 & Incluir observações quando necessário & Sec. Pós-grad. \\
\hline 6.5.3.4 & Encaminhar observações por e-mail & Sistema TDE \\
\hline 6.5 .4 & Providenciar correçôes & Pós-graduando \\
\hline 6.5.4.1 & Receber e-mail com observações da SPG & Pós-graduando \\
\hline 6.5.4.2 & Realizar correções se necessário & Pós-graduando \\
\hline 6.5.4.3 & Enviar e-mail informando correções para SPG & Pós-graduando \\
\hline 6.5 .5 & Providenciar documentação final de aprovação (teses homologadas) & Sec. Pós-grad. \\
\hline 6.5 .6 & Finalizar correções & Sec. Pós-grad. \\
\hline 6.5.6.1 & Receber e-mail informando correções & Sec. Pós-grad. \\
\hline 6.5.6.2 & Colocar senha no arquivo PDF quando estiver OK & Sec. Pós-grad. \\
\hline 6.5.6.3 & Liberar Tese/Dissertação para catalogação & Sec. Pós-grad. \\
\hline 6.5.6.4 & $\begin{array}{l}\text { Encaminhar aviso de disponibilidade para catalogação } \\
\text { por e-mail }\end{array}$ & Sistema TDE \\
\hline 6.6 & Encaminhar versão impressa da tese/dissertação para a Biblioteca & Sec. Pós-grad. \\
\hline 7 & TORNAR DISPONÍVEL TESE OU DISSERTAÇÃO & \\
\hline 7.1 & Receber versão impressa da tese ou dissertação & Biblioteca \\
\hline 7.2 & Receber aviso da SPG por email & Biblioteca \\
\hline 7.3 & $\begin{array}{l}\text { Verificar teses/dissertações disponíveis para } \\
\text { catalogar diariamente }\end{array}$ & Biblioteca \\
\hline 7.3.1 & Revisar dados bibliográficos da tese/dissertação & Biblioteca \\
\hline 7.3 .2 & Gerar arquivo MARC & Biblioteca \\
\hline 7.3.3 & Importar registro MARC para catalogação & Biblioteca \\
\hline 7.3 .4 & Complementar dados no Sistema DEDALUS & Biblioteca \\
\hline 7.3.5 & Catalogar tese/dissertação na Biblioteca Digital & Biblioteca \\
\hline 7.4 & Depositar versão impressa na estante & Biblioteca \\
\hline 8 & GERENCIAR DADOS DO SISTEMA & \\
\hline 8.1 & Fazer estatísticas do site & Adm. Sistema \\
\hline 8.2 & Enviar estatísticas do site aos interessados & Adm. Sistema \\
\hline 8.3 & Administrar dados dos usuários da biblioteca digital & Adm. Sistema \\
\hline
\end{tabular}

- muitos autores pensam em publicar suas teses em forma de livros, principalmente na área de ciências humanas, e isso poderia causar problemas de direito autoral, perda de receita etc.;

- muitos autores, principalmente nas áreas de ciências básicas, têm a preocupação de que se possa perder a originalidade do trabalho, prejudicando a publicação de artigos sobre a tese em periódicos, pedidos de patentes, registro de espécimes (biologia) etc.;

- de forma mais velada, alguns deixaram transparecer uma preocupação quanto à qualidade do trabalho, principalmente em relação à redação, o que ficaria mais exposto na Biblioteca Digital.
Para contornar essas situações, foram adotadas algumas soluções técnicas. A principal é permitir que as teses sejam inseridas e fiquem "retidas" pelo período de um ano, que pode ser estendido. Nesse caso, as teses não podem ter o conteúdo consultado, mas os seus dados bibliográficos, incluindo o resumo, e até as referências bibliográficas, ficam disponíveis para consulta. Há também a possibilidade de liberar para consulta apenas parte da tese (alguns capítulos, p. ex.) deixando outros retidos.

Outra decisão importante foi quanto ao depósito obrigatório ou não da versão digital. Considerando-se os pontos discutidos anteriormente, que, se exacerbados, poderiam inviabilizar o projeto, e, ainda, as particularidades e o grau desejado de descentralização dos 
programas de pós-graduação na USP, o Conselho de Pósgraduação decidiu que, em sua fase inicial, a submissão da versão digital será voluntária, devendo essa questão voltar a ser discutida no futuro. Com base nessa decisão, a Comissão iniciou um plano de comunicação para divulgar a Biblioteca Digital e incentivar a participação dos alunos e orientadores.

Há dois receios verbalizados com freqüência pelos orientadores quanto ao conteúdo do texto digital armazenado pelo autor. Um refere-se à mudança do texto após a defesa, isto é, sobre a possibilidade de que o aluno corrija a tese na versão digital, levando em conta as observações dos examinadores. Outro é que o aluno submeta a tese com mudanças em relação ao exemplar defendido, sem autorização do orientador, ou submeta, sem perceber, um arquivo com erros.

O sistema é neutro em relação ao primeiro caso, que deve ser resolvido por uma decisão administrativa. Há várias alternativas: manter as versões digital e impressa da mesma forma, manter o exemplar impresso como foi defendido e inserir na Biblioteca Digital o exemplar corrigido etc. Para o segundo caso, o sistema fornece dois pontos de controle. O primeiro é efetuado pela seção de pó-graduação, que insere e confere os dados relativos à tese provenientes do sistema de pós-graduação (banca examinadora, data da defesa, título etc.) e nesse momento abre os arquivos submetidos pelo aluno e faz uma conferência superficial. O segundo é efetuado nas bibliotecas, que também abrem os arquivos quando inserem os dados bibliográficos e fazem uma conferência geral, antes de liberar a tese para consulta.

\section{CONSIDERAÇÕES FINAIS}

Discutiram-se neste trabalho alguns dos aspectos mais importantes da implementação da Biblioteca Digital de Teses e Dissertações da Universidade de São Paulo. A Biblioteca está implantada, mas ainda há muitos desafios para garantir o sucesso do projeto. Entre as várias atividades em andamento, estão a melhoria da documentação do site e a criação de relatórios para os coordenadores de pós-graduação e para os orientadores, novos treinamentos para os funcionários e a criação e instalação do Comitê Gestor do Portal.

No momento, a Comissão encarregada da implementação está envolvida no povoamento retrospectivo da base. Para isso, todos os alunos que defenderam suas teses após o dia primeiro de janeiro de 2000 estão sendo convidados a inseri-las. Uma força-tarefa composta por estagiários foi alocada para auxiliar e até mesmo realizar, temporariamente, o trabalho. O Conselho de Pós- graduação, junto com a Comissão, deve discutir, ainda, a regulamentação formal do uso da Biblioteca, bem como um projeto de digitalização retrospectiva das teses defendidas antes de 2000.

\section{REFERÊNCIAS BIBLIOGRÁFICAS}

1. BIBLIOTECA digital de teses e dissertações da USP. Disponível em: $<$ http://www.teses.usp.br>.

2. FOX, E. A.; MARCHIONINI, G. Digital libraries. Communications of the ACM, v. 44, n. 1, p. 88-89, May 2001.

3. URS, S. R.; RAGHAVAN, K. S. Vidyanidhi: Indian digital library of electronic theses. Communications of the ACM, v. 44, n. 1, p. 88-89, May 2001.

4. UNIVERSIDADE DE SÃO PAULO (São Paulo, SP). Portaria GR 3225/2000. Diário Oficial do Estado de São Paulo, São Paulo, v.110, n.141, 25 jul. 2000

5. NETWORKED digital libraries of theses and dissertations. Disponível em: <http://www.ndltd.ogr >.

6. Portal do conhecimento da USP. Disponível em: <http:// www.saber.usp.br $>$.

7. INSITE. Disponível em: <http://www.insite.com.br>.

8. UNIVERSIDADE DE SÃO PAULO (São Paulo, SP). Disponível em: $<$ http://www.usp.br $>$. 